\title{
Pharmacologic and Non-Pharmacologic Treatment of Osteoarthritis
}

\section{Erlangga Yusuf, MD, PhD}

\author{
Address \\ UZ Brussel (University Hospital Brussels), Laarbeeklaan 101, 1090, Jette, Belgium \\ Email: angga.yusuf@gmail.com
}

Published online: 5 April 2016

(C) Springer International Publishing AG 2016

This article is part of the Topical Collection on Osteoarthritis

Keywords 0steoarthritis - Weight reduction · Acetaminophen · NSAIDs · Total joint replacement

\section{Opinion statement}

Osteoarthritis $(\mathrm{OA})$ is not merely a degenerative disease but a disease of the whole joint. The aims of $O A$ treatment are to alleviate pain and to improve function. The effect of pharmacologic and non-pharmacologic treatment in $\mathrm{OA}$ as shown by randomized control trials (RCTs) is often small or moderate. The treatment should be therefore personalized since not every patient will benefit from a specific treatment. The combination of nonpharmacologic with pharmacologic treatment will give the best result. It is important to educate the patient about the aim of $0 \mathrm{~A}$ treatment to increase therapeutic adherence. Since obesity is one of the most important risk factors for having $0 \mathrm{~A}$ progression, losing weight should be advised. Losing weight can be achieved by diet or by performing exercise. Exercise without joint movement (isometric exercise) should be tried first in patients who cannot perform high-impact exercise. When pain is bearable and joint function is not severely limited, isotonic exercise such as walking, biking, and swimming can be prescribed. The first-line pharmacologic $\mathrm{OA}$ treatment is acetaminophen to treat mild and intermittent symptoms. If the symptoms are getting worse or when acetaminophen is not sufficient to relieve pain, non-steroidal anti-inflammatory drugs (NSAIDs) can be used. Risk profile of having gastric ulcer complication and cardiovascular risk factor should be assessed prior to prescribing NSAIDs. In case of refractory pain after nonpharmacologic and pharmacologic treatment, total joint replacement (TJR) can be considered. The patient should be willing to have surgery and have no relative contraindication. Morbid obesity might be a contraindication for TJR. Studies on drugs that not only improve symptoms but also halt further damage of the joint, the so-called diseasemodifying $O A$ drugs, are ongoing. Several examples of the drugs are anakinra, adalimumab, and doxycycline. At present, there is no solid evidence whether these drugs can indeed be used as disease-modifying osteoarthritis drugs (DMOADs). 


\section{Introduction}

Clinically, osteoarthritis (OA) is characterized by pain, stiffness, cracking of the joints (crepitus), and loss of function of the joint which can lead to disability. The disease occurs commonly in elderly [1]. The most common affected joints by OA seen on radiograph (radiographic OA) are hand followed by knee and hip joints $[2,3]$. Multiple joints can be involved, and this will cause greater impact on health than $\mathrm{OA}$ in a single joint [4]. In the past, $\mathrm{OA}$ was considered as degenerative disorder that involved only cartilage. Now, OA is considered as a disease that involves the whole joint structures: synovium, subchondral bone, and infrapatellar fat pad $[5,6 \bullet \bullet, 7]$. Once $\mathrm{OA}$ is diagnosed, the symptoms and the damage of the joint can get worse, remain the same, or rarely getting better [8]. Several risk factors for worsening of OA (i.e., OA progression) are known such as older age, female sex, obesity, genetic predisposition, and malalignment [9]. Obesity is a part metabolic syndrome, a syndrome that consists of interrelated risk factors of metabolic origins such as hypertension, dyslipidemia, and insulin resistance [10]. It is increasingly acknowledged that $\mathrm{OA}$ is associated with metabolic syndrome or its components. Perhaps, obesity leads to OA not only due to additional mechanical force exerted to the weight-bearing joints but also due to metabolic factors $[11 \bullet$, 12].

The shift in OA paradigm from degenerative joint disease to inflammatory joint disease and increasing insight into the metabolic role in OA have led to new opportunities for OA treatment. At present, the purposes of $\mathrm{OA}$ treatment are to alleviate pain and to improve the function of the joint by pharmacologic and nonpharmacologic means [13]. Next to these goals, OA treatment should also halt or slow down joint damage. Logically, when the joint damage can be halted, symp-

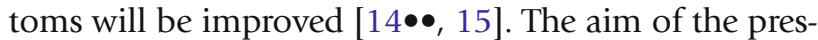
ent paper is to review the present treatment options (Table 1) for OA including studies on drugs that might modify joint structure in OA patients.

\section{Treatment}

\section{Diet and weight loss}

Since being overweight is a risk factor for worsening of OA, losing weight by means of dietary weight loss is an intervention that can be recommended to the patient. Studies on weight loss interventions have often been studied in knee OA patients, and they have shown moderate benefit [16]. Christensen and coworkers performed in 2007 a meta-analysis on the effect of weight reduction in obese patients diagnosed with knee OA [16]. They included four studies performed by two research groups, and they showed significant effect size for pain and physical disability of 0.20 (95\% CI 0 to 0.39 ) and 0.23 (0.04 to 0.42$)$ at a weight reduction of $6.1 \mathrm{~kg}$ ( 4.7 to $7.6 \mathrm{~kg}$ ). These effect sizes are considered clinically as small [17]. When Lequesne index, a measure of pain intensity and functional limitation of patients with hip and/or knee diseases [18], was used, the pooled effect size in this meta-analysis was moderate $(0.58$ (95\% CI -0.4 to 1.6) but not statistically significant. The authors of this meta-analysis concluded that symptomatic relief can be experienced if patients can reduce their body weight at least by $5 \%$ within a 20 -week period. Comparable effect is shown in patients with hip OA as shown in another Cochrane meta-analysis.

\section{Physical therapy and exercise}

The primary aims of performing exercise in OA patients are to reduce symptom and to improve functional performance of the joint $[19,20,21 \bullet \bullet]$. By doing exercise, weight loss can also be achieved [19]. Prescribing exercise to treat OA is a delicate balance. Patients with OA might have pain and limited function and 


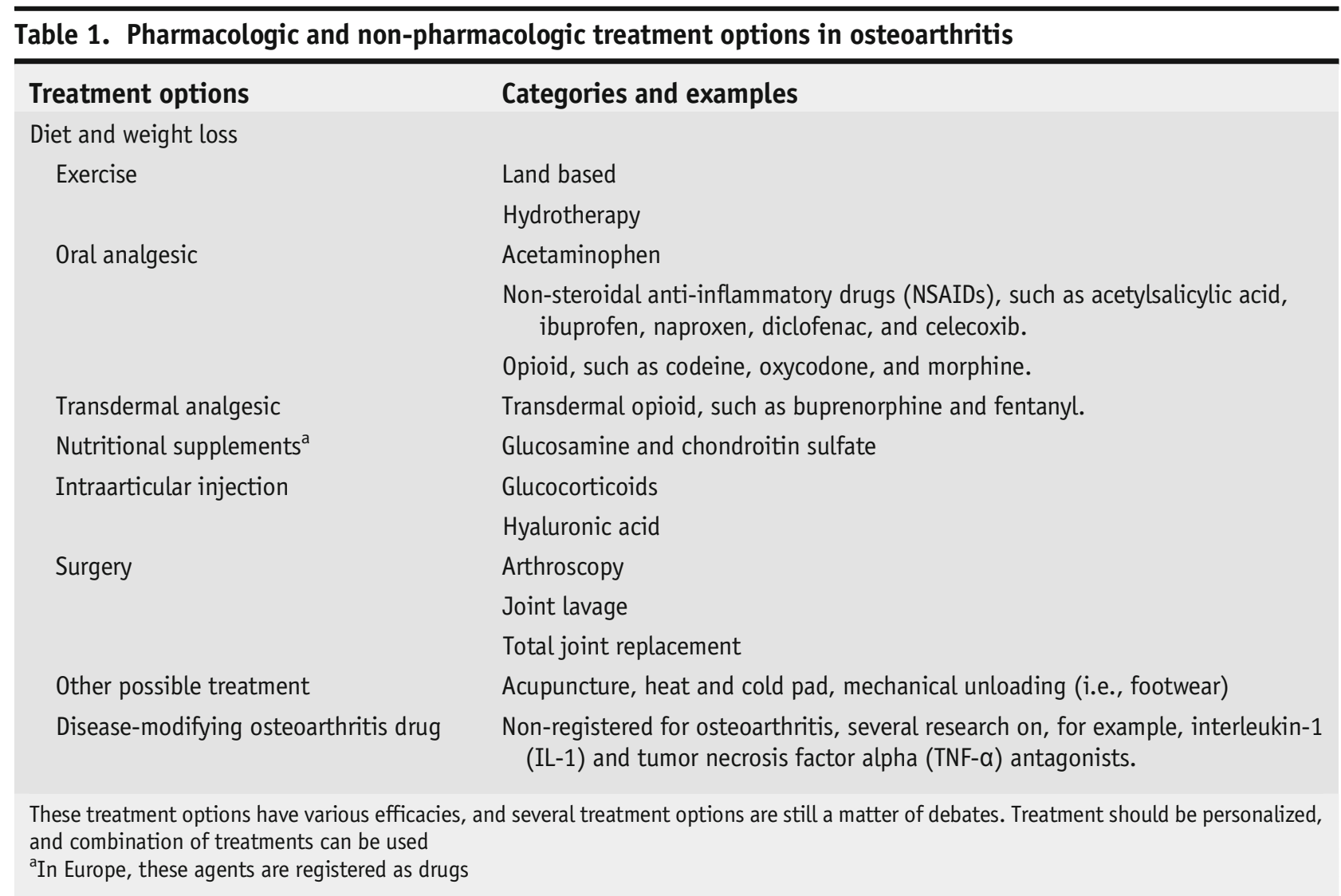

not capable to perform exercise. Moreover, high-impact activities are shown to have negative effect on OA [22-24]. Individualization of exercise based on patient's condition and preference is therefore needed. Static (isometric) exercise, i.e., exercise without involvement of the joint, can be advised in patients with too painful joint or with limited function of the joint. An example of this type of exercise is isometric quadricep exercise. Patient in a supine position with a rolled up towel under the knee is asked to maximally activate his thigh muscles and hold the contraction for $5 \mathrm{~s}$ [25]. Isotonic exercise that encompasses any moving exercise such as walking and biking might be advised to patients who are able to do so [19]. It is important to give adequate advice and education to promote exercise since there might be problem with adherence. Even in a study, the adherence to exercise program was below $75 \%$ [26••].

\section{Land-based exercise program}

A recent Cochrane meta-analysis compared patients with knee OA who performed exercise programs such as muscle strengthening training and aerobic fitness with patients who did not exercise [27]. This meta-analysis that included 44 studies showed that exercise reduced pain by 12 points (95\% CI 10 to 15 points) in a scale of 0 to 100 immediately after intervention. Exercise also improved physical function by 10 points ( $95 \%$ CI 8 to 13 points) in a scale of 0 to 100 . This effect is shown to be sustained for at least 2 to 6 months after 
stopping the exercise. The authors of this review concluded that these immediate effects should be considered as moderate [27].

\section{Aquatic exercise (hydrotherapy)}

Aquatic exercises have several possible benefits above land-based exercise therapy. Since water buoyancy reduces the compressive load that joints have to sustain, it can be used in patients with difficulties in exercising on the land under normal conditions of gravity which is difficult and painful [28]. Moreover, water can be heated to $32-36{ }^{\circ} \mathrm{C}$ and this warmth might also reduce swelling and increase blood circulation [29].

The effect of hydrotherapy in OA is shown in a meta-analysis, but the effect is minor, i.e., decrease of pain by 0.6 point on a scale 0 to 20 and $6.6 \%$ relative reduction from baseline for pain in patients with knee and hip OA [30].

\section{Pharmacologic treatment}

At present, the goal of drug therapy in OA is to alleviate symptoms, but, ideally, drug therapy in OA should modify the damage of joint structures and consequently reduce the pain and increase the function of the joint. Arguably, nonsteroidal anti-inflammatory drugs (NSAIDs), one of the drug classes used to alleviate symptoms in OA, could have the potential to modify the structure damaged in OA, such as the synovium, but this has not been demonstrated in clinical studies in OA. Interestingly, it has been reported that NSAIDs might act as disease-modifying agent in ankylosing spondylitis [31]. At present, there are

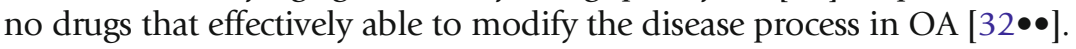

\section{Acetaminophen (paracetamol)}

Acetaminophen is an inexpensive analgesic that is considered as first-line drug therapy in OA [33]. It can be used intermittently when mild pain occurs. It should not be used continuously since it does not have structure modification effect. Patients should use acetaminophen to a maximum of $4 \mathrm{~g} /$ day. A Cochrane meta-analysis that included five RCTs in its analysis showed that the use of paracetamol led to pain reduction by four points (on a 0 to 100 scale) over that achieved with placebo and to $5 \%$ improvement from baseline [34]. This level of pain reduction is confirmed in a more recent meta-analysis for immediate ( $\leq 2$ weeks) and short-term effects (between 2 weeks and 3 months) [35]. Acetaminophen did not show significant immediate effect in improving function and showed short-term improvement of function by three points on a 0 to 100 scale [35].

In a meta-analysis, there was no difference shown in the number of patients reporting adverse events between the paracetamol and placebo groups [35]. Acetaminophen does cause mild side effect such as stomach upset and gastric ulcers, especially in high dose [36].

\section{Non-steroidal anti-inflammatory drugs}

NSAIDs are relatively inexpensive drugs that have analgesic, anti-inflammatory, and anti-pyretic effects. They work by inhibiting cyclooxygenase-2 (COX-2) and usually also COX-1 enzymes, which are involved in prostaglandin synthesis. There are several classes of NSAIDs. Acetylsalicylic acid (aspirin) is an example 
of salicylate group. Ibuprofen is a derivate of propionic acid that can be given as low dose (400 mg thrice daily) or medium dose (600 mg thrice daily) with the maximum of $3200 \mathrm{mg} /$ day [37]. Another example of derivate of propionic acid is naproxen, which can be given as low dose (250 mg thrice daily) or medium dose (500 mg twice daily), with a maximum of $1250 \mathrm{mg} /$ day [37]. Diclofenac is an example from the phenylacetic acid group, which can be given as $50 \mathrm{mg}$ twice daily (low dose) or $75 \mathrm{mg}$ twice daily (medium dose), with a maximum of $200 \mathrm{mg} /$ day [37]. Celecoxib is an example of NSAIDs that specifically inhibits COX-2 enzymes. It can be given in low dose (200 $\mathrm{mg}$ once a day) or in medium/maximum dose of $200 \mathrm{mg}$ twice daily [37].

Acetylsalicylic acid is a non-prescription drug while other NSAIDs do need prescription in most of the countries in the world. Care should be taken in prescribing NSAIDs by taking drug history of patients, because concurrent uses of acetylsalicylic acid and other NSAIDs are risk factors of having gastrointestinal side effect such as peptic ulcer [ $38 \bullet \bullet$. Deciding which NSAIDs to use can be based on the safety profile. Even low dose of acetylsalicylic acid can cause peptic ulcer, and the risk increases with increasing dose [39]. COX-2 inhibitors and ibuprofen are considered to be NSAIDs with the least peptic ulcer side effects [40]. When an OA patient has high risk for peptic ulcer bleeding, for example due to a previous bleeding ulcer, consider first other possible therapy. If NSAIDs need to be prescribed in such patients, COX-2 inhibitors can be used together with gastroprotective agents such as misoprostol (standard dose $200 \mu \mathrm{g}$ once daily) or a high-dose proton pump inhibitor (such as omeprazole $40 \mathrm{mg}$ once

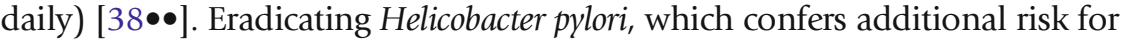
gastrointestinal bleeding [41], should be considered when patients might re-

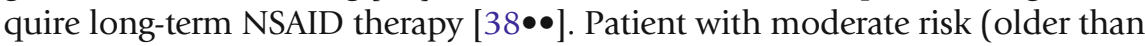
65 years, using high-dose NSAIDs, previous history of uncomplicated ulcer) may use non-selective NSAIDs together with a gastroprotective agent. When no risk for peptic ulcer bleeding is present, an NSAID can be administered without gastroprotective co-therapy. Peptic ulcers due to NSAIDs can be healed by stopping the NSAID therapy in most cases [42].

NSAIDs might also increase cardiovascular events as has been shown with COX-2 inhibitors and with high-dose diclofenac and ibuprofen [43]. Among NSAIDs, the risk of cardiovascular events is shown to be lower with naproxen $[44,45]$. NSAIDs can also cause slight increase in blood pressure, and this increase is mostly dose dependent [46].

\section{Opioid analgesics}

Opioid analgesics can be given by mouth, as an injection or through transdermal patch [47]. Oral opioid analgesics can be classified based on their analgesic potencies [48]. Codeine is an example of oral opioid with low analgesic potency. Oxycodone and morphine are examples of oral opioid with high analgesic potency. Transdermal opioid analgesics used in OA are often from the strongest analgesic potency, such as buprenorphine and fentanyl. Compared to placebo, opioid analgesics lead to relative significant pain improvement, 0.7$\mathrm{cm}$ lower pain on a 10-cm visual analogue scale [49]. However, opioid analgesic use even for short term is associated with adverse effects [49]. The adverse events occur in all dose range but more often in higher dose [50]. The most common side effects are gastrointestinal (such as constipation and dry mouth) 
and central nervous systems (such as problems with sleep (25\%), memory deficits $(24 \%)$ ) [50]. These side effects are mostly reversible but often cause the patients to stop the treatment [51]. Constipation is the side effect that often does not improve with time and laxation is needed [49]. Next to the potential adverse events, opioid analgesics are drugs with abuse potential. Therefore, it is better to reserve opioid analgesics for the patients in whom other analgesics have failed to relieve pain or for patients contraindicated or who are not willing to have surgery. It is difficult to give a dose advice on opioid analgesics in OA. In general, the qualified patients can be put on low-dose opioids and the dose can be lowered as needed and/or in function of the patient's tolerance. Several dose examples used in RCTs in OA patients were $10 \mathrm{mg}$ twice daily for codeine [52] and $20 \mathrm{mg}$ oxycodone [53].

Tramadol is considered as an atypical opioid. Unlike other opiates, it is considered to be less associated with adverse events such as constipation and has less significant abuse potential [54]. The recommended dosage is 50 to $100 \mathrm{mg}$ every 4 to $6 \mathrm{~h}$ [54]. Perhaps, when opioid analgesic must be used, tramadol can be used first. Yet, the use of this agent is limited by the development of tolerance.

The transdermal opioid shows comparable adverse events as oral opioid but is thought to be more tolerable [55]. In an RCT, transdermal fentanyl patch that released fentanyl $25 \mu \mathrm{g} / \mathrm{h}$ led to significant pain reduction compared to placebo [55].

\section{Topical analgesics}

Topical analgesics can be used for local treatment of the OA joint when the symptoms are relatively mild. Capsaicin and topical NSAIDs are among the active ingredients of topical analgesics [56]. An RCT on topical use of cis-isomer of capsaicin showed an intermediate- (up to 84 days) and long-term (up to 52week) pain relief [57].

\section{Glucosamine and chondroitin sulfate}

In Europe, glucosamine and chondroitin sulfate are registered as drugs while in North America as dietary supplements [58]. Several meta-analysis and systematic review have been published on whether these drugs can reduce the pain and reduce the joint space narrowing $[59,60 \bullet, 61]$ Despite these publications, the debate on the use of these drugs is still ongoing. According to Cochrane metaanalysis, glucosamine, chondroitin, and the combination of glucosamine and chondroitin show slight pain reduction of around 0.3 to $0.5 \mathrm{~cm}$ on a $10-\mathrm{cm}$ visual analogue scale for pain compared to placebo in hip and knee OA patients [60•]. This clinical effect is considered as minimal. Again, the finding of minimal effect might suggest that there is subpopulation of OA that might be benefit from these drugs [62], and this should be sought in RCTs. In unselected OA population, the use of glucosamine or chondrotin is not cost-effective [63].

\section{Intraarticular glucocorticoids}

Glucocorticoids have shown anti-inflammatory effects [64] and can inhibit the production of the collagenases that mediate cartilage damage in OA $[65,66]$. Intraarticular glucocorticoids can be used in OA, especially in patients who are 
not improved with NSAIDs treatment. There are several systematic reviews concerning the use of intraarticular corticosteroids in OA [67-69], and they showed relatively similar results. A recent Cochrane meta-analysis that included 27 trials concluded that compared to placebo, intraarticular corticosteroids lead to ten-point reduction of pain on a scale of 0 to 100 [68]. The effect is mainly observed 1 week after injection and lasts up to 4 to 6 weeks $[68,69]$. Comparable effect and duration of effect were also seen for improvement in function [68]. Of note, the included studies in the meta-analysis were heterogeneous. Arguably, there will be subtypes of OA patients that may benefit from glucocorticoids more than other subtypes, for example, patients with notable synovitis. Synovitis has been shown to be associated with pain [70•]. However, synovitis was not shown to be a predictor of pain reduction in knee and hip OA after intraarticular injection of glucocorticoids [71].

It is difficult to give an evidence-based recommendation on which glucocorticoid to use because of the limited number of studies. The glucocorticoids used are often based on personal/clinical experience [72]. The author, for example, uses methylprednisolone. A meta-analysis showed that injection of triamcinolone in knee and hip joints is significantly more effective in reducing pain at week 3 in comparison to methylprednisolone, but there is no difference in immediate effect between these glucocorticoids [69]. In this meta-analysis, it was also shown that triamcinolone was better in reducing pain than betamethasone at week 1 . The dose of glucocorticoids to be used depends on the joints. Methylprednisolone acetate or triamcinolone acetonide can be given in 20 to $40 \mathrm{mg}$ ( $1 \mathrm{ml}$ ) for a large joint (shoulder, knee, and ankle). Intraarticular glucocorticoids can be given up to once every 3 months [73•], but other therapies should be considered first.

The most feared complication of intraarticular injection of glucocorticoid is septic arthritis. Yet, the incidence is very low, $<0.08 \%[72,74]$. In fact, the most common complication is the worsening of pain within 24 to $48 \mathrm{~h}$ after having an injection (postinjection flare) which might occur to up to $10 \%$ of the injected patients [72].

\section{Intraarticular hyaluronic acid}

Hyaluronic acid supplementation is believed to be useful to alleviate symptoms in OA joint $[75,76]$ because hyaluronic acid, which plays a role in viscoelastic characteristics of the synovial fluid, was shown to be of lower concentration in OA than normal joint [77]. This relatively expensive viscosupplement [78] is available as naturally occurring hyaluronan and as synthetic hylan G-F 20. Compared to placebo, viscosupplements were shown in a Cochrane review to improve pain and function by approximately up to 54 and $32 \%$ compared with baseline levels, respectively, in the 5- to 13-week postinjection period [79]. Yet, another review showed a less significant effect [80]. Despite the publication of meta-analysis and systematic review, it is still debatable whether intraarticular hyaluronic acid should be given for OA treatment $[76,81]$.

The efficacy and the safety profile of intraarticular hyaluronic acid and intraarticular glucocorticoids are considered comparable [82]. They should be reserved for patients who failed exercise and oral pharmacologic treatments and who are contraindicated or reluctant to have joint 
replacement surgery. Several authors prefer to perform initial glucocorticoid injection, and when it fails, the patient is switched to intraarticular hyaluronic acid [82]

\section{Surgery}

Surgery is an invasive procedure that should be performed when the nonpharmacological and pharmacological treatments fail to show desired effect. Total joint replacement is considered as a definitive treatment of OA that reduces pain and restores function.

\section{Arthroscopy}

A Cochrane meta-analysis published in 2008 that summarized data of 271 patients showed no benefit of arthroscopic debridement compared to sham surgery placebo in knee OA [83]. Arthroscopic debridement should indeed not be performed in treating knee OA. There is anecdotal evidence that arthroscopy does have benefit in a subtype of patients, i.e., in patients with an isolated medial femoral chondral lesion [84].

\section{Joint lavage}

Joint lavage shows small benefit in terms of pain relief at 3 months: $0.3-\mathrm{cm}$ pain reduction and 0.2-cm function improvement compared to control on a $10-\mathrm{cm}$ visual analogue scale [85]. This effect is too small to include joint lavage as a standard armamentarium of OA treatment considering the potential severe side effects such as septic arthritis and the need of dedicated facilities. Again, there are patients that might benefit of joint lavage such as OA patient with predominant synovitis because joint lavage might wash out the inflammatory factors present in the joint.

\section{Total joint replacement}

Total joint replacement is considered as the definitive treatment of OA. Several studies showed significant improvement of pain and function after joint replacement surgery $[86,87 \bullet \bullet]$. Patients who underwent total knee replacement followed by a 12 -week non-surgical treatment program (consisted of exercise, education, dietary advice, use of insoles, and pain medication) showed significant pain relief and improving function and quality of life after 12 months (measured using Knee Injury and Osteoarthritis Outcome Score) compared to patients who received 12-week non-surgical treatment program only $[87 \bullet \bullet]$. However, this treatment is associated with more significant serious adverse events such as deep venous thrombosis and infection $[87 \bullet \bullet]$. Therefore, patients who need knee or hip joint replacement should be selected $[88,89]$. It is estimated that up to $25 \%$ of persons are not suitable candidates for joint replacement and have poor outcomes [88]. The selection should be based on the patient's clinical symptoms and preference and surgical characteristics $[89,90 \bullet]$. The pain should be substantial that causes significant limitation in daily activities. The pain should be refractive to conservative treatments such as pain medication and exercise. Often, the decision for surgery is taken in patients with severe pain in function 
limitation after reviewing joint radiograph showing severe joint space narrowing or large osteophytes. The patient should be able to undergo surgery, i.e., not having significant medical disease that outweighs the possible benefit of joint replacement surgery. The local vascular supply and the soft tissue cover should also be sufficient. (Morbid) obesity can be a contraindication for joint replacement surgery since it increases the risk of infection after surgery [91]. There is often hesitancy in performing total joint replacement in older patients. Older patients ( $>65$ years old) do recover slower than younger patients, but the outcome is, in general, excellent [92].

Total joint replacement is not performed only for large joint such as knee and hip, but can also be performed for hand joint such as carpometacarpal and interphalangeal joints $[93,94]$.

\section{Other treatments}

\section{Acupuncture}

Compared to sham control, acupuncture improves pain by four points on a scale of 0 to 20 after 8 weeks and by three points after 26 weeks in patients with knee or hip OA. This is a minimal added benefit compared to sham acupuncture (pain reduction of three points after 8 and 26 weeks) [95]. Yet, compared to usual care group, acupuncture shows a more clinical relevant improvement in pain and function in short and longer terms [96•]. Perhaps, acupuncture might of benefit in a select group of patients with moderate OA.

\section{Heat and cold pad}

Patients mention sometimes that applying heat or cold pad reduces the pain or improves the function of a joint. This practice is not evidence-based, but it is an inexpensive method, and arguably, cold pad can reduce the blood flow to the joint and might reduce joint swelling. On the other hand, applying hot pad might relax the stiff joints.

\section{Orthosis}

Mechanical loading and misalignment are risk factors for OA progression of weight-bearing joints [97•]. Reducing this load may be able to reduce OA progression. Non-surgical means to unload can be achieved by using orthosis, such as shoe insert and brace [98]. While orthosis can be considered as inexpensive, no solid evidence on the benefit of knee bracing or laterally wedged insole is shown in knee OA patients [99].

\section{Emerging therapies: disease-modifying osteoarthritis drugs}

At present, the treatment of $\mathrm{OA}$ is thus merely aimed at symptomatic treatment and there is no treatment aimed at halting structural damage of the joint. Since structural damage is related with symptoms and functions $[70 \bullet]$, such a drug, so-called disease-modifying osteoarthritis drugs (DMOADs) can be expected to improve OA symptoms. There are several logical targets in DMOADs such as synovial inflammation mediators, inhibitors of cartilage degradation, and inhibitor of subchondral bone 


\section{Conclusions}

remodeling [100]. Interleukin-1 (IL-1) and tumor necrosis factor alpha $($ TNF- $\alpha$ ) are inflammatory factors involved in OA. Studies on DMOADs on inflammatory mediators have been performed, often in hand OA phenotypes. A preliminary study shows pain reduction and global disability in patients with erosive hand OA after daily subcutaneous injections of IL-1 receptor antagonist (Anakinra) for 3 months [101•]. Anti-TNF- $\alpha$ adalimumab is shown to halt progression of joint damage compared to placebo in interphalangeal joints of patients with erosive hand OA [102•]. Metalloproteinases (MMPs) play a role in the destruction of the cartilage and bone damage in OA [103]. Doxycycline, an antibiotic that is also a potent inhibitor of MMPs, is shown to be able to reduce the rate of joint space narrowing in the medial tibiofemoral compartment of knee joint compared to placebo in obese women [104•].

The treatment of OA patient is discussed based on published evidence. In general, non-pharmacological treatment consists of diet and exercise. Pharmacological treatment includes acetaminophen, NSAIDs, and topical analgesic. When all of these treatments fail, total joint replacement might be considered. Researches on DMOADs are ongoing, and they might be on the horizon.

Of note, most of the meta-analyses on OA treatment show minimal or moderate effect of the therapy, perhaps because of the heterogeneity in the study population. Arguably, not every OA patient will benefit from a specific OA treatment and the treatment should be therefore personalized. In order to do this, studies on a specific OA treatment should only include patients who might benefit the most from the specific treatment. For example, a drug that mainly works as anti-inflammatory should be tested in OA patient with synovitis as a predominant clinical sign. Such studies are clearly needed.

\section{Acknowledgments}

The author performs his work on osteoarthritis mainly when he was at the Department of Rheumatology at Leids Universitair Medisch Centrum (LUMC) in Leiden, The Netherlands, with Prof. Dr. G. Kloppenburg.

\section{Compliance with Ethical Standards}

\section{Conflict of Interest}

EY declares that he has no conflict of interest.

Human and Animal Rights and Informed Consent

This article does not contain any studies with human or animal subjects performed by any of the authors. 


\section{References and Recommended Reading}

Papers of particular interest, published recently, have been highlighted as:

- Of importance

$\bullet \quad$ Of major importance

1. Shane Anderson A, Loeser RF. Why is osteoarthritis an age-related disease? Best Pract Res Clin Rheumatol. 2010;24:15-26. doi:10.1016/j.berh. 2009.08.006.

2. Felson DT, Lawrence RC, Dieppe PA, Hirsch R, Helmick CG, Jordan JM, et al. Osteoarthritis: new insights-part 1: the disease and its risk factors. Ann Intern Med. 2000;133:635-46. doi:10.7326/00034819-133-8-200010170-00016.

3. van Saase JL, van Romunde LK, Cats A, Vandenbroucke JP, Valkenburg HA. Epidemiology of osteoarthritis: Zoetermeer survey. Comparison of radiological osteoarthritis in a Dutch population with that in 10 other populations. Ann Rheum Dis. 1989;48:271-80. doi:10.1136/ard.48.4.271.

4. Nelson AE, Smith MW, Golightly YM, Jordan JM. "Generalized osteoarthritis": a systematic review. Semin Arthritis Rheum. 2014;43:713-20. doi:10. 1016/j.semarthrit.2013.12.007.

5. Klein-Wieringa IR, Kloppenburg M, BastiaansenJenniskens YM, Yusuf E, Kwekkeboom JC, El-Bannoudi $\mathrm{H}$, et al. The infrapatellar fat pad of patients with osteoarthritis has an inflammatory phenotype. Ann Rheum Dis. 2011;70:851-7. doi:10.1136/ard.2010. 140046.

6.• Scanzello CR, Goldring SR. The role of synovitis in osteoarthritis pathogenesis. Bone. 2012;51:249-57. doi:10.1016/j.bone.2012.02.012.

An in-depth review of the involvement of synovitis in osteoarthritis.

7. Goldring MB, Goldring SR. Articular cartilage and subchondral bone in the pathogenesis of osteoarthritis. Ann N Y Acad Sci. 2010;1192:230-7. doi:10.1111/j. 1749-6632.2009.05240.x.

8. E. Yusuf, J. Bijsterbosch, P.E. Slagboom, H.M. Kroon, F.R. Rosendaal, T.W.J. Huizinga, et al., Association between several clinical and radiological determinants with long-term clinical progression and good prognosis of lower limb osteoarthritis, PLoS One. 6 (2011).

9. Yusuf E, Nelissen RG, Ioan-Facsinay A, StojanovicSusulic V, DeGroot J, van Osch G, et al. Association between weight or body mass index and hand osteoarthritis: a systematic review. Ann Rheum Dis. 2010;69:761-5.

10. Eckel RH, Grundy SM, Zimmet PZ. The metabolic syndrome. Lancet. 2005;365:1415-28. doi:10.1016/ S0140-6736(05)66378-7.

11. Yoshimura N, Muraki S, Oka H, Kawaguchi H, Nakamura K, Akune T. Association of knee osteoarthritis with the accumulation of metabolic risk factors such as overweight, hypertension, dyslipidemia, and impaired glucose tolerance in Japanese men and women: the ROAD study. J Rheumatol. 2011;38:92130. doi:10.3899/jrheum.100569.

A relatively large study that investigated the association between knee osteoarthritis and metabolic risk factors.

12. Han CD, Yang IH, Lee WS, Park YJ, Park KK. Correlation between metabolic syndrome and knee osteoarthritis: data from the Korean National Health and Nutrition Examination Survey (KNHANES). BMC Public Health. 2013;13:603. doi:10.1186/1471-2458-13-603.

13. Zhang W, Moskowitz RW, Nuki G, Abramson S, Altman RD, Arden N, et al. OARSI recommendations for the management of hip and knee osteoarthritis, part II: OARSI evidence-based, expert consensus guidelines. Osteoarthr Cartil. 2008;16:137-62. doi:10.1016/j.joca. 2007.12.013.

$14 . \bullet$ Brandt KD. Why should we expect a structure-modifying osteoarthritis drug to relieve osteoarthritis pain? Ann Rheum Dis. 2011;70:1175-7.

An editorial regarding the joint components that might serve as targets for disease-modifying osteoarthritis drugs.

15. Snijders GF, van den Ende $\mathrm{CH}$, van Riel PL, van den Hoogen FH, den Broeder AA. The effects of doxycycline on reducing symptoms in knee osteoarthritis: results from a triple-blinded randomised controlled trial. Ann Rheum Dis. 2011;70:1191-6. doi:10.1136/ard.2010. 147967.

16. Christensen R, Bartels EM, Astrup A, Bliddal H. Effect of weight reduction in obese patients diagnosed with knee osteoarthritis: a systematic review and metaanalysis. Ann Rheum Dis. 2007;66:433-9. doi:10. 1136/ard.2006.065904.

17. J. Cohen (1988) Statistical power analysis for the behavioral sciences 10.1234/12345678

18. Dawson J, Linsell L, Doll H. Assessment of the Lequesne index of severity for osteoarthritis of the hip in an elderly population. Osteoarthr Cart. 2005;13:854-60. doi:10.1016/j.joca.2005.05.006.

19. Hunter DJ, Eckstein F. Exercise and osteoarthritis. J Anat. 2009;214:197-207. doi:10.1111/j.1469-7580. 2008.01013.x.

20. Bennell KL, Hinman RS, Metcalf BR, Buchbinder R, McConnell J, McColl G, et al. Efficacy of physiotherapy management of knee joint osteoarthritis: a randomised, double blind, placebo controlled trial. Ann Rheum Dis. 2005;64:906-12. doi:10.1136/ard. 2004.026526.

21.• Ettinger WH, Burns R, Messier SP, Applegate W, Rejeski WJ, Morgan T, et al. A randomized trial comparing aerobic exercise and resistance exercise with a health education program in older adults with knee osteoarthritis. The Fitness Arthritis and Seniors Trial (FAST). 
JAMA. 1997;277:25-31. doi:10.1001/jama.1997. 03540250033028.

A well performed randomized control trial on the effect of exercise in osteoarthritis.

22. Saxon L, Finch C, Bass S. Sports participation, sports injuries and osteoarthritis: implications for prevention. Sports Med. 1999;28:123-35. doi:10.2165/00007256199928020-00005.

23. Buckwalter JA. Sports, joint injury, and posttraumatic osteoarthritis. J Orthop Sports Phys Ther. 2003;33:578-88. doi:10.2519/jospt.2003.33.10.578.

24. Spector TD, Harris PA, Hart DJ, Cicuttini FM, Nandra D, Etherington J, et al. Risk of osteoarthritis associated with long-term weight-bearing sports: a radiologic survey of the hips and knees in female ex-athletes and population controls. Arthritis Rheum. 1996;39:98895. doi:10.1002/art.1780390616.

25. Anwer S, Alghadir A. Effect of isometric quadriceps exercise on muscle strength, pain, and function in patients with knee osteoarthritis: a randomized controlled study. J Phys Ther Sci. 2014;26:745-8. doi:10. 1589/jpts.26.745.

26.• Messier SP, Loeser RF, Miller GD, Morgan TM, Rejeski WJ, Sevick MA, et al. Exercise and dietary weight loss in overweight and obese older adults with knee osteoarthritis: the arthritis, diet, and activity promotion trial. Arthritis Rheum. 2004;50:1501-10. doi:10.1002/art. 20256.

A relatively large study on the effect of weight loss in osteoarthritis.

27. Fransen M, Mcconnell S. Exercise for osteoarthritis of the knee (review). Cochrane Libr. 2015. doi:10.2522/ ptj.20100084.

28. Poumyhumlnen T, Keskinen KL, Kyroumlauminen $\mathrm{H}$, Hautala A, Savolainen J, Maumllkiauml E. Neuromuscular function during therapeutic knee exercise under water and on dry land. Arch Phys Med Rehabil. 2001;82:1446-52. doi:10.1053/apmr.2001.25073.

29. Biscarini A, Cerulli G. Modeling of the knee joint load in rehabilitative knee extension exercises under water. J Biomech. 2007;40:345-55. doi:10.1016/j.jbiomech. 2005.12.018.

30. Bartels EM, Lund H, Hagen KB, Dagfinrud H, Christensen R, Danneskiold-Samsøe B. Aquatic exercise for the treatment of knee and hip osteoarthritis. Cochrane Database Syst Rev. 2007. doi:10.2340/ 16501977-0134.

31. Inman RD, Haroon N, Kim TH. NSAIDs and radiographic progression in ankylosing spondylitis bagging big game with small arms? Ann Rheum Dis. 2012;71:1593-5.

32.• Qvist P, Bay-Jensen AC, Christiansen C, Dam EB, Pastoureau P, Karsdal MA. The disease modifying osteoarthritis drug (DMOAD): is it in the horizon? Pharmacol Res. 2008;58:1-7. doi:10.1016/j.phrs.2008. 06.001 .

A good review on disease-modifying osteoarthritis drugs.

33. Wise J. NICE keeps paracetamol in UK guidelines on osteoarthritis. BMJ. 2014;348:g1545.
34. Towheed TE, Maxwell L, Judd MG, Catton M, Hochberg MC, Wells G. Acetaminophen for osteoarthritis. Cochrane Database Syst Rev. 2006. doi:10. 1002/14651858.CD004257.

35. Machado GC, Maher CG, Ferreira PH, Pinheiro MB, Lin C-WC, Day RO, et al. Efficacy and safety of paracetamol for spinal pain and osteoarthritis: systematic review and meta-analysis of randomised placebo controlled trials. BMJ. 2015;350:h1225. doi:10.1136/bmj.h1225.

36. Bannwarth B. Gastrointestinal safety of paracetamol: is there any cause for concern? Expert Opin Drug Saf. 2004;3:269-72. http://www.ncbi.nlm.nih.gov/ pubmed/15268644.

37. Chou R, McDonagh M, Nakamoto E, (2011) Analgesics for osteoarthritis: an update of the 2006 comparative effectiveness review, Agency Fo Healthc. Res. Qual. http://www.ncbi.nlm.nih.gov/books/NBK65646/ http://www.ncbi.nlm.nih.gov/pubmed/22091473

38.• Lanza FL, Chan FKL, Quigley EMM. Guidelines for prevention of NSAID-related ulcer complications. Am J Gastroenterol. 2009;104:728-38. doi:10.1038/ajg. 2009.115.

A guideline on the peptic ulcer associated NSAIDs and how to prevent it. An important read for doctors who prescribe NSAIDs.

39. Weil J, Colin-Jones D, Langman M, Lawson D, Logan R, Murphy M, et al. Prophylactic aspirin and risk of peptic ulcer bleeding. BMJ. 1995;310:827-30. doi:10.1136/ bmj.310.6983.827.

40. Baigent C, Bhala N, Emberson J, Merhi A, Abramson S, Arber N, et al. Vascular and upper gastrointestinal effects of non-steroidal anti-inflammatory drugs: meta-analyses of individual participant data from randomised trials. Lancet. 2013;382:769-79. doi:10.1016/S0140-6736(13) 60900-9.

41. Huang JQ, Sridhar S, Hunt RH. Role of helicobacter pylori infection and non-steroidal anti-inflammatory drugs in peptic-ulcer disease: a meta-analysis. Lancet. 2002;359:14-22. doi:10.1016/S0140-6736(02) 07273-2.

42. Davies NM. Sustained release and enteric coated NSAIDs: are they really GI safe? J Pharm Pharm Sci. 2006;2:5-14. http://www.ncbi.nlm.nih.gov/pubmed/ 10951657.

43. European Medicine Agency, Updated advice on use of high-dose ibuprofen, (2015). http://www.ema.europa. eu/docs/en_GB/document_library/Press_release/ 2015/05/WC500187108.pdf (accessed January 1, 2016).

44. Pawlosky N. Cardiovascular risk: are all NSAIDs alike? Can Pharm J / Rev Des Pharm Du Canada. 2013;146:80-3. doi:10.1177/1715163513481569.

45. Ray WA. Cardiovascular safety of NSAIDs. BMJ. 2011;342:c6618. doi:10.1136/bmj.c6618.

46. Johnson A, Nguyen TV, Day R. Do nonsteroidal antiinflammatory drugs affect blood pressure? A metaanalysis. Ann Intern Med. 1994;121:289-300. doi:10. 7326/0003-4819-121-4-199408150-00011. 
47. Knotkova H, Fine PG, Portenoy RK. Opioid rotation: the science and the limitations of the equianalgesic dose table. J Pain Symptom Manag. 2009;38:426-39. doi:10.1016/j.jpainsymman.2009.06.001.

48. Fine PG, Portenoy RK. Establishing "best practices" for opioid rotation: conclusions of an expert panel. J Pain Symptom Manag. 2009;38:418-25. doi:10.1016/j. jpainsymman.2009.06.002.

49. Sehgal N, Colson J, Smith HS. Chronic pain treatment with opioid analgesics: benefits versus harms of longterm therapy. Expert Rev Neurother. 2013;13:1201-20. doi:10.1586/14737175.2013.846517.

50. Kalso E, Edwards JE, Moore RA, McQuay HJ. Opioids in chronic non-cancer pain: systematic review of efficacy and safety. Pain. 2004;112:372-80. doi:10.1016/j. pain.2004.09.019.

51. Avouac J, Gossec L, Dougados M. Efficacy and safety of opioids for osteoarthritis: a meta-analysis of randomized controlled trials. Osteoarthr Cartil. 2007;15:95765. doi:10.1016/j.joca.2007.02.006.

52. G.J. Vlok, J.P. van Vuren, Comparison of a standard ibuprofen treatment regimen with a new ibuprofen/ paracetamol/codeine combination in chronic osteoarthritis., S. Afr. Med. J. Suppl (1987) 1, 4-6.

53. Caldwell JR, Hale ME, Boyd RE, Hague JM, Iwan T, Shi $\mathrm{M}$, et al. Treatment of osteoarthritis pain with controlled release oxycodone or fixed combination oxycodone plus acetaminophen added to nonsteroidal antiinflammatory drugs: a double blind, randomized, multicenter, placebo controlled trial. J Rheumatol. 1999;26:862-9. http://www.ncbi.nlm.nih.gov/ pubmed/10229408.

54. W.A. Katz, Pharmacology and clinical experience with tramadol in osteoarthritis, Drugs. 52 Suppl 3 (1996) 39-47. h

55. Langford R, McKenna F, Ratcliffe S, Vojtassák J, Richarz $U$. Transdermal fentanyl for improvement of pain and functioning in osteoarthritis: a randomized, placebocontrolled trial. Arthritis Rheum. 2006;54:1829-37. doi:10.1002/art.21884.

56. Argoff CE. Topical analgesics in the management of acute and chronic pain. Mayo Clin Proc. 2013;88:195205. doi:10.1016/j.mayocp.2012.11.015.

57. Schnitzer TJ, Pelletier J-P, Haselwood DM, Ellison WT, Ervin JE, Gordon RD, et al. Civamide cream $0.075 \%$ in patients with osteoarthritis of the knee: a 12-week randomized controlled clinical trial with a longterm extension. J Rheumatol. 2012;39:610-20. doi:10. 3899/jrheum.110192.

58. Henrotin Y, Marty M, Mobasheri A. What is the current status of chondroitin sulfate and glucosamine for the treatment of knee osteoarthritis? Maturitas. 2014;78:184-7. doi:10.1016/j.maturitas.2014.04.015.

59. Ho Y, Woo LJ, Jae S, Jong C, Ji D, Gyu G, et al. Effect of glucosamine or chondroitin sulfate on the osteoarthritis progression: a meta-analysis. Rheumatol Int 2010;30:357-63. doi:10.1007/s00296-009-0969-5.

60. Wandel S, Juni P, Tendal B, Nuesch E, Villiger PM, Welton NJ, et al. Effects of glucosamine, chondroitin, or placebo in patients with osteoarthritis of hip or knee: network meta-analysis. BMJ. 2010;341:c4675. doi:10.1136/bmj.c4675.

An interesting meta-analysis on controversial drugs in osteoarthritis treatment.

61. Rozendaal RM, Uitterlinden EJ, van Osch GJVM, Garling EH, Willemsen SP, Ginai AZ, et al. Effect of glucosamine sulphate on joint space narrowing, pain and function in patients with hip osteoarthritis; subgroup analyses of a randomized controlled trial. Osteoarthritis Cart. 2009;17:427-32. doi:10.1016/j.joca. 2008.05.022.

62. Clegg DO, Reda DJ, Harris CL, Klein MA, O'Dell JR, Hooper MM, et al. Glucosamine, chondroitin sulfate, and the two in combination for painful knee osteoarthritis. N Engl J Med. 2006;354:795-808. doi:10.1056/ NEJMoa052771.

63. Black C, Clar C, Henderson R, MacEachern C, McNamee P, Quayyum Z, et al. The clinical effectiveness of glucosamine and chondroitin supplements in slowing or arresting progression of osteoarthritis of the knee: a systematic review and economic evaluation. Health Technol Assess (Rockv). 2009;13:1-123. doi:10.3310/hta13520.

64. Saklatvala J. Glucocorticoids: do we know how they work? Arthritis Res. 2002;4:146-50. doi:10.1186/ ar398.

65. Pelletier JP, Martel-Pelletier J, Cloutier JM, Woessner JF. Proteoglycan-degrading acid metalloprotease activity in human osteoarthritic cartilage, and the effect of intraarticular steroid injections. Arthritis Rheum. 1987;30:541-8.

66. Lohmander LS, Hoerrner LA, Lark MW. Metalloproteinases, tissue inhibitor, and proteoglycan fragments in knee synovial fluid in human osteoarthritis. Arthritis Rheum. 1993;36:181-9. doi:10.1002/art. 1780360207.

67. Godwin M, Dawes M. Intra-articular steroid injections for painful knees. Systematic review with meta-analysis. Can Fam Physician. 2004;50:241-8.

68. P. Jüni, R. Hari, R. Aws, R. Fischer, S. Mg, S. Reichenbach, et al., Intra-articular corticosteroid for knee osteoarthritis (Review), Cochrane Database Syst. Rev. (2015). 10.1002/14651858.CD005328.pub3

69. Hepper CT, Halvorson JJ, Duncan ST, Gregory AJM, Dunn WR, Spindler KP. The efficacy and duration of intra-articular corticosteroid injection for knee osteoarthritis: a systematic review of level I studies. J Am Acad Orthop Surg. 2009; 17:638-46.

70. Yusuf E, Kortekaas MC, Watt I, Huizinga TWJ, Kloppenburg M. Do knee abnormalities visualised on MRI explain knee pain in knee osteoarthritis? A systematic review. Ann Rheum Dis. $2011 ; 70: 60-7$

An interesting systematic review on the joint components that might be involved in $\mathrm{OA}$, whether they cause pain.

71. Hirsch G, Kitas G, Klocke R. Intra-articular corticosteroid injection in osteoarthritis of the knee and hip: factors predicting pain relief-a systematic review. 
Semin Arthritis Rheum. 2013;42:451-73. doi:10. 1016/j.semarthrit.2012.08.005.

72. Stephens MB, Beutler AI, O'Connor FG. Musculoskeletal injections: a review of the evidence. Am Fam Physician. 2008;78:971-6.

73. $\quad$ Raynauld JP, Buckland-Wright C, Ward R, Choquette D, Haraoui B, Martel-Pelletier J, et al. Safety and efficacy of long-term intraarticular steroid injections in osteoarthritis of the knee: a randomized, double-blind, placebo-controlled trial. Arthritis Rheum. 2003;48:370-7. doi:10.1002/art.10777.

A study with relatively long follow-up on an controversial issue in treatment of osteoarthritis.

74. Courtney P, Doherty M. Joint aspiration and injection and synovial fluid analysis. Best Pract Res Clin Rheumatol. 2013;27:137-69. doi:10.1016/j.berh. 2013.02.005.

75. Wen DY. Intra-articular hyaluronic acid injections for knee osteoarthritis. Am Fam Physician. 2000;62:565-70.

76. Hunter DJ. Viscosupplementation for osteoarthritis of the knee. N Engl J Med. 2015;372:1040-7.

77. Moreland LW. Intra-articular hyaluronan (hyaluronic acid) and hylans for the treatment of osteoarthritis: mechanisms of action. Arthritis Res Ther. 2003;5:5467. doi:10.1186/ar623.

78. Arrich J, Piribauer F, Mad P, Schmid D, Klaushofer K, Müllner M. Intra-articular hyaluronic acid for the treatment of osteoarthritis of the knee: systematic review and meta-analysis. CMAJ. 2005;172:1039-43. doi:10.1503/cmaj.1041203.

79. B. N, C. J, W. V, G. Tl, B. R, W. Ga, et al., Viscosupplementation for the treatment of osteoarthritis of the knee ( Review ), Cochrane Database Syst. Rev. (2009) 1-3. doi:Copyright.

80. Colen S, van den Bekerom MP, Mulier M, Haverkamp D. Hyaluronic acid in the treatment of knee osteoarthritis: a systematic review and meta-analysis with emphasis on the efficacy of different products. BioDrugs. 2012;26:257-68. doi:10.2165/11632580-00000000000000 .

81. A.A. of O.S. (AAOS), Treatment of osteoarthritis of the knee" 2nd edition, 2013. http://www.aaos.org/ research/guidelines/

OAKSummaryofRecommendations.pdf.

82. Keith MP. Updates on intra-articular hyaluronic acid therapy for knee osteoarthritis. Am J Orthop. 2012;41(4):E61-3.

83. W. Laupattarakasem, M. Laopaiboon, P. Laupattarakasem, C. Sumananont, L. W, L. M, et al., Arthroscopic debridement for knee osteoarthritis., Cochrane Database Syst. Rev. (2008) CD005118. doi:10.1002/14651858.CD005118.pub2.

84. Griffin D, Barlow T, Downham C. Arthroscopy in knee osteoarthritis: a systematic review of the literature. Acta Orthop Belg. 2015;81:1-8.

85. Reichenbach $S$, Rutjes AW, Nüesch E, Trelle S, Jüni P. Joint lavage for osteoarthritis of the knee. Cochrane Database Syst Rev. 2010. doi:10.1002/14651858. CD007320.
86. C.A. Jones, D.C. Voaklander, D.W.C. Johnston, M.E. Suarez-Almazor, Health related quality of life outcomes after total hip and knee arthroplasties in a community based population, J. Rheumatol. 27 (2000) 1745-1752. http://ovidsp.ovid.com/ovidweb. cgi? $\mathrm{T}=\mathrm{JS} \& \mathrm{CSC}=\mathrm{Y} \& \mathrm{NEWS}=\mathrm{N} \& \mathrm{PAGE}=$ fulltext $\& \mathrm{D}=$ emed5\&AN=2000255208 http://sfx.leidenuniv. $\mathrm{nl}: 9003 /$ sfx_local?sid=OVID:Embase\&issn $=0315$ $162 \mathrm{X}$ \&isbn $=$ \&volume $=27$ \&issue $=7$ \&spage $=$ $1745 \&$ date $=2000$ \&pid $=<$ author $>$ Jones + C.A. $<*$ uthor $>$ $<28$. $>$.

87.• Skou ST, Roos EM, Laursen MB, Rathleff MS, ArendtNielsen L, Simonsen O, et al. A randomized, controlled trial of total knee replacement-supplement. N Engl J Med. 2015;373:1597-606. doi:10.1056/ NEJMoa1505467.

A proof of principal, randomized control trial on why total knee replacement is considered as a definitive treatment in osteoarthritis.

88. Dowsey MM, Gunn J, Choong PFM. Selecting those to refer for joint replacement: who will likely benefit and who will not? Best Pract Res Clin Rheumatol. 2014;28:157-71. doi:10.1016/j.berh.2014.01.005.

89. Zeni JA, Axe MJ, Snyder-Mackler L. Clinical predictors of elective total joint replacement in persons with endstage knee osteoarthritis. BMC Musculoskelet Disord. 2010;11:86. doi:10.1186/1471-2474-11-86.

90. Crawford RW, Murray DW. Total hip replacement: indications for surgery and risk factors for failure. Ann Rheum Dis. 1997;56:455-7. doi:10.1136/ard.56.8.455.

A good review on total hip replacement in osteoarthritis.

91. Namba RS, Paxton L, Fithian DC, Lou Stone M. Obesity and perioperative morbidity in total hip and total knee arthroplasty patients. J Arthroplasty. 2005;20:4650. doi:10.1016/j.arth.2005.04.023.

92. Hamel M, Toth M, Legedza A, Rosen M. Joint replacement surgery in elderly patients with severe osteoarthritis of the hip or knee: decision making, postoperative recovery, and clinical outcomes. Arch Intern Med. 2008;168:1430-40. doi:10.1016/j.ijsu.2014.07.014.

93. Matullo KS, Ilyas A, Thoder JJ, Ibrahim MS, Jordan RW, Kallala R, et al. Total proximal interphalangeal joint arthroplasty for osteoarthritis versus rheumatoid arthritis-a systematic review. Hand Surg. 2015;20:232-9. doi:10.1007/s11552-007-9068-9.

94. K.S. Matullo, A. Ilyas, J.J. Thoder, CMC arthroplasty of the thumb: a review., Hand (N. Y). 2 (2007) 232-9. doi:10.1007/s11552-007-9068-9.

95. S. van der W.D.B.B.M.B.L. Manheimer, Eric; Cheng Ke; Linde Klaus, Lao, Lixing; Yoo, Junghee; Wieland, Acupuncture for peripheral joint osteoarthritis, Cochrane Database Syst Rev. 20(1) (2010) CD001977.

96. Manheimer E, Linde K, Lao L, Bouter LM, Berman BM. Meta-analysis: acupuncture for osteoarthritis of the knee. Ann Intern Med. 2007;146:868-77.

An interesting meta-analysis on controversial treatment method in osteoarthritis treatment.

97. Yusuf E, Bijsterbosch J, Slagboom PE, Rosendaal FR, Huizinga TW, Kloppenburg M. Body mass index and 
alignment and their interaction as risk factors for progression of knees with radiographic signs of osteoarthritis. Osteoarthr Cartil. 2011;19:1117-22. doi:10. 1016/j.joca.2011.06.001.

An epidemiology study on the interaction of two risk factors of osteoarthritis progression.

98. F.P.J.G. Lafeber, F. Intema, P.M. Van Roermund, A.C. a Marijnissen, Unloading joints to treat osteoarthritis, including joint distraction., Curr. Opin. Rheumatol. 18 (2006) 519-525. doi:10.1097/01.bor.0000240366. 54960.a1.

99. B.-Z.S. Duivenvoorden T, Brouwer RW, van Raaij TM, Verhagen AP, Verhaar JAN, Braces and orthoses for treating osteoarthritis of the knee, Cochrane Database Syst. Rev. (2015). doi:10.1002/14651858.CD004020. pub3.

100. J.P. Pelletier, J. Martel-Pelletier, DMOAD developments: present and future, Bull. NYU Hosp. Jt. Dis. 65 (2007) 242-248. papers://46aa81df-5122-41ef-ac15$44 \mathrm{e} 17 \mathrm{~cd} 711 \mathrm{ef} /$ Paper/p138.

101. Fabre S, Bacconnier L, Jorgensen C. Erosive osteoarthritis of the hand: clinical experience with anakinra. Ann Rheum Dis. 2009;68:1078-9.
A preliminary study on the use of a possible disease-modifying osteoarthritis drug in a subtype of osteoarthritis predominantly characterized by inflammation.

102.• Verbruggen G, Wittoek R, Cruyssen BV, Elewaut D. Tumour necrosis factor blockade for the treatment of erosive osteoarthritis of the interphalangeal finger joints: a double blind, randomised trial on structure modification. Ann Rheum Dis. 2012;71:891-8. doi:10.1136/ard.2011.149849.

A preliminary study on the use of a possible disease-modifying osteoarthritis drug in a subtype of osteoarthritis predominantly characterized by inflammation.

103. G. Murphy, M.H. Lee, What are the roles of metalloproteinases in cartilage and bone damage?, Ann. Rheum. Dis. 64 Suppl 4 (2005) iv44-v47. doi:10. 1136/ard.2005.042465.

104. Brandt KD, Mazzuca SA, Katz BP, Lane KA, Buckwalter KA, Yocum DE, et al. Effects of doxycycline on progression of osteoarthritis: results of a randomized, placebo-controlled, double-blind trial. Arthritis Rheum. 2005;52:2015-25. doi:10.1002/art.21122.

A preliminary study on the use of a possible disease-modifying osteoarthritis drug. 